\title{
Erratum to: Evidence against a direct role of klotho in insulin resistance
}

\author{
Olivier Lorenzi • Christelle Veyrat-Durebex • Claes B. Wollheim • Pascal Villemin • \\ Françoise Rohner-Jeanrenaud • Anne Zanchi • Ulrich M. Vischer
}

Published online: 13 April 2010

(C) Springer-Verlag 2010

\section{Erratum to: Pflugers Arch - Eur J Physiol}

DOI 10.1007/s00424-009-0735-2

The elements of the author's name were wrongly coded in the metadata of this article, with the result that the name was listed incorrectly in all indexing services. His given name is Ulrich M.; his surname, Vischer.

\footnotetext{
The online version of the original article can be found under http://dx. doi.org/10.1007/s00424-009-0735-2.

O. Lorenzi • C. B. Wollheim · P. Villemin · U. M. Vischer Department of Cell Physiology and Metabolism, Faculty of Medicine, University of Geneva,

Geneva, Switzerland

U. M. Vischer

Department of Rehabilitation and Geriatrics, Faculty of Medicine, University of Geneva,

Geneva, Switzerland

C. Veyrat-Durebex $\cdot$ F. Rohner-Jeanrenaud Department of Internal Medicine, Division of Endocrinology, Diabetology and Nutrition, Faculty of Medicine,

University of Geneva,

Geneva, Switzerland

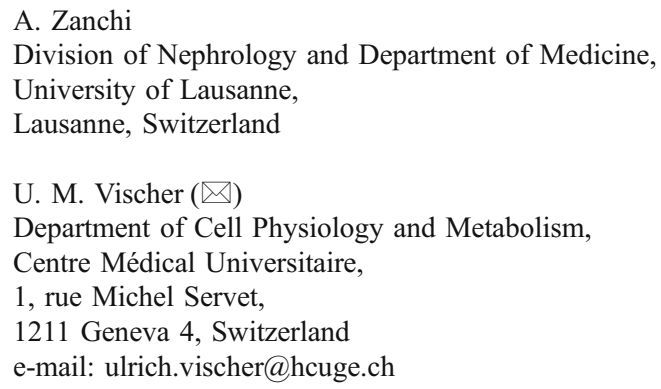

